\title{
Rapid Identification of Aldose Reductase Inhibitory Compounds from Perilla frutescens
}

\author{
Ji Hun Paek, ${ }^{1}$ Kuk Hyun Shin, ${ }^{2}$ Young-Hee Kang, ${ }^{1,3}$ Jae-Yong Lee, ${ }^{4,5}$ and Soon Sung Lim ${ }^{1,3,5}$ \\ ${ }^{1}$ Department of Food Science and Nutrition, Hallym University, 1 Hallymdaehak-gil, \\ Chuncheon, Gangwon-do 200-702, Republic of Korea \\ ${ }^{2}$ Korea Institute of Science and Technology Information, Seoul 130-741, Republic of Korea \\ ${ }^{3}$ Department of Center for Aging and Health Care, Hallym University, 1 Hallymdaehak-gil, \\ Chuncheon, Gangwon-do 200-702, Republic of Korea \\ ${ }^{4}$ Department of Biochemistry, School of Medicine, Hallym University, 1 Hallymdaehak-gil, \\ Chuncheon, Gangwon-do 200-702, Republic of Korea \\ ${ }^{5}$ Institute of Natural Medicine, Hallym University, 1 Hallymdaehak-gil, Chuncheon, Gangwon-do 200-702, Republic of Korea
}

Correspondence should be addressed to Soon Sung Lim; limss@hallym.ac.kr

Received 23 April 2013; Accepted 11 September 2013

Academic Editor: Kota V. Ramana

Copyright (C) 2013 Ji Hun Paek et al. This is an open access article distributed under the Creative Commons Attribution License, which permits unrestricted use, distribution, and reproduction in any medium, provided the original work is properly cited.

The ethyl acetate (EtOAc) soluble fraction of methanol extracts of Perilla frutescens (P. frutescens) inhibits aldose reductase (AR), the key enzyme in the polyol pathway. Our investigation of inhibitory compounds from the EtOAc soluble fraction of $P$. frutescens was followed by identification of the inhibitory compounds by a combination of HPLC microfractionation and a 96-well enzyme assay. This allowed the biological activities to be efficiently matched with selected HPLC peaks. Structural analyses of the active compounds were performed by LC-MS ${ }^{\mathrm{n}}$. The main AR inhibiting compounds were tentatively identified as chlorogenic acid and rosmarinic acid by LC-MS ${ }^{\mathrm{n}}$. A two-step high speed counter current chromatography (HSCCC) isolation method was developed with a solvent system of $n$-hexane-ethyl acetate-methanol-water at $1.5: 5: 1: 5, \mathrm{v} / \mathrm{v}$ and $3: 7: 5: 5, \mathrm{v} / \mathrm{v}$. The chemical structures of the isolated compounds were determined by ${ }^{1} \mathrm{H}$ - and ${ }^{13} \mathrm{C}$-nuclear magnetic resonance spectrometry (NMR). The main compounds inhibiting AR in the EtOAc fraction of methanol extracts of $P$. frutescens were identified as chlorogenic acid $(2)\left(\mathrm{IC}_{50}=3.16 \mu \mathrm{M}\right)$, rosmarinic acid (4) $\left(\mathrm{IC}_{50}=2.77 \mu \mathrm{M}\right)$, luteolin $(5)\left(\mathrm{IC}_{50}=6.34 \mu \mathrm{M}\right)$, and methyl rosmarinic acid $(6)\left(\mathrm{IC}_{50}=4.03 \mu \mathrm{M}\right)$.

\section{Introduction}

Long-term secondary diabetic complications are the main cause of morbidity and mortality in diabetic patients [1]. Recent human genetic and biochemical data link polymorphisms of the aldose reductase (AR) gene (technically called the AR2 gene) and elevated tissue levels of AR with strongly altered risks for diabetic complications [2]. Due to its proposed involvement in diabetic complications, ALR2 has been a drug target in the clinical management of diabetes [3]. Numerous clinical trials and experimental animal studies have shown that early intervention is required to achieve maximal reduction in the onset and severity of diabetic retinopathy and cataracts [4]. Natural or synthetic compounds such as flavonoids, benzopyrans, spirohydantoins, and quinones inhibit the enzyme with various degrees of activity and specificity $[5,6]$.

Perilla frutescens ( $P$. frutescens) is an annual short-day plant belonging to the family Labiatae [7]. It has long been used as traditional folk medicine for anxiety, tumor, cough, bacterial and fungal infections, allergy, intoxication, and some intestinal disorders [8-11]. P. frutescens possesses antiinflammatory, antitumor, and antiallergic activities [12]. Previous chemical studies on leaves and seeds of $P$. frutescens have reported the presence of sterols: b-sitosterol, stigmasterol, and campesterol; terpenoids: ursolic and acid, oleanolic acid, and tormentic acid; anthocyanin: shisonin; flavonoids: apigenin, luteolin, and scutellarein; and phenolic acids: rosmarinic acid, caffeic acid, and ferulic acid [13-16]. Therefore, we investigated the inhibitory effect of the dried leaves of 
P. frutescens on AR to evaluate its potential in treating diabetic complications. The goal of this study was to identify the active constituents of $P$. frutescens by enzyme assay-guided HPLC microfractionation and to improve our understanding of how the active compound of $P$. frutescens acts against rAR.

\section{Materials and Methods}

2.1. Apparatus and Reagents. DL-Glyceraldehyde, the reduced form of nicotinamide adenine dinucleotide phosphate (NADPH), sodium phosphate, and quercetin used in this study, was purchased from Sigma-Aldrich (St. Louis, MO, USA). All other chemicals and reagents used were of analytical grade.

2.2. Plant Materials. P. frutescens was purchased from a local market in Chuncheon, Rebublic of Korea. A voucher sample (RIC-2012-5) has been deposited at the Center for Efficacy Assessment and Development of Functional Foods and Drugs, Hallym University, Chuncheon. The specimens were authenticated by Emeritus Professor H. J. Chi, Seoul National University, Rebublic of Korea.

2.3. Extraction. Dried leaves of $P$. frutescens $(2 \mathrm{~kg})$ were extracted 3 times with $99.5 \%$ methanol for $5 \mathrm{~h}$. The solvent was evaporated under reduced pressure below $45^{\circ} \mathrm{C}$ to give a methanol extract (yield: 11.68\%). The extract was suspended in distilled water and partitioned with $n$-hexane ( $n$-Hex), methylene chloride $\left(\mathrm{CH}_{2} \mathrm{Cl}_{3}\right)$, ethyl acetate (EtOAc), $n$ butanol $(n-\mathrm{BuOH})$, and $\mathrm{H}_{2} \mathrm{O}$ to yield $n$-Hex $(40.83 \mathrm{~g})$, EtOAc (25.20 g), $\mathrm{CH}_{2} \mathrm{Cl}_{3}$ (22.24 g), $n-\mathrm{BuOH}$ (116.88 g), and $\mathrm{H}_{2} \mathrm{O}$ fractions (27.42 g). In total, 6 fractions were obtained. A small amount of each fraction was dissolved in dimethyl sulfoxide (DMSO) and assayed for AR inhibitory activity.

2.4. HPLC Microfractionation. An automated fraction collector (Foxy 200; ISCO, Lincoln, NE, USA) coupled with HPLC equipment (Thermo Electron Spectra HPLC system; Thermo Separation Products, San Jose, CA, USA) was used to separate and collect compounds from extracts directly into 96-well plates (Nunc, Roskilde, Denmark) at $0.4 \mathrm{~mL} /$ well (Figure 1). HPLC separation was achieved with Agilent Eclips XDB-C18 columns $(150 \times 4.6 \mathrm{~mm}, 5 \mu \mathrm{m}$, Agilent Tech., Palo Alto, CA, USA). The mobile phase, consisting of acetonitrile (ACN) and $0.1 \%$ aqueous trifluoroacetic acid (TFA), was used at a flow rate of $0.8 \mathrm{~mL} / \mathrm{min}$. The gradient elution program was $7.5-$ $26.5 \%$ B (0-20 min), 26.5\% B (20-30 min), 26.5-36\% B (30$40 \mathrm{~min})$, and $36-100 \% \mathrm{~B}(40-45 \mathrm{~min})$. Injection volume was $10 \mu \mathrm{L}$ at sample concentration $10 \mathrm{mg} / \mathrm{mL}$ and detection wavelength $280 \mathrm{~nm}$. After collection, all fractions were evaporated to dryness using an EZ-2 plus evaporator (Gene Vac Ltd., Ipswich, UK).

2.5. Validation of HPLC Microfractionation Assays. The effect on rAR inhibitory activity (\%) was calculated as the change in absorbance in a sample well versus the change in absorbance in a blank well (average, $n=12$ ). Spontaneous hydrolysis was subtracted from the reaction rate. The hit limit was set

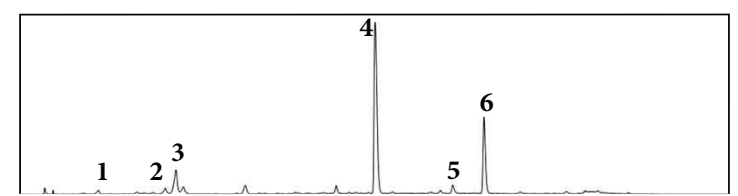

(a)

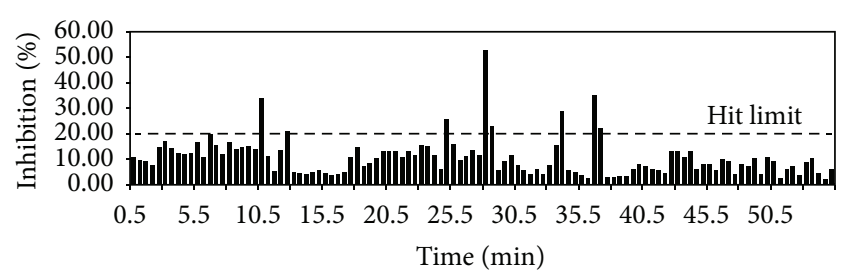

(b)

FIgURE 1: HPLC chromatogram (a) and active profile (b) of the HPLC microfractionated of EtOAc soluble fraction of $P$. frutescens for rAR inhibition in 96-well plate.

at 3 standard deviations (SD) from the minimum AR inhibitory activity. $Z^{\prime}$-factor, signal-to-background ratio $(S / B)$ [17], and signal-to-noise $\operatorname{ratio}(S / N)$ [18] were used to evaluate the quality of the test: $Z^{\prime}=1\left[\left(3 \times \mathrm{SD}_{s}+3 \times \mathrm{SD}_{b}\right) /\left|X_{s} X_{b}\right|\right]$, $S / B=X_{s} / X_{b}$, and $S / N=\left(X_{s} X_{b}\right) /\left(\mathrm{SD}_{s}{ }^{2}+\mathrm{SD}_{b}{ }^{2}\right)^{1 / 2} ; X_{s}$ and $\mathrm{SD}_{s}$ are average and standard deviation of the signal, that is, absorption detected at the 8th measurement point in blank wells $(n=12)$ after adding the enzyme; $X_{b}$ and $\mathrm{SD}_{b}$ are average and SD of the background, that is, absorption at the first measurement point in blank wells $(n=12)$ after adding the enzyme.

2.6. LC/DAD/ESI-MS ${ }^{n}$ Analysis. The EtOAc extracts were analyzed by HPLC-PDA. In order to acquire chromatograms and UV spectra, we used the Finnigan Surveyor HPLC system (Thermo Electron, San Jose, CA, USA), which comprised a PDA plus detector, autosampler plus, a column compartment, and MS pump plus. The samples were separated on an Eclipse SB-C18 Rapid Resolution column $(150 \times 4.6 \mathrm{~mm}, 3.5 \mu \mathrm{m}$, Agilent) with a C18 guard column $(7.5 \times 4.6 \mathrm{~mm}$, i.d. $3.5 \mu \mathrm{m}$, Alltech) using $0.1 \%$ trifluoroacetic acid (TFA) in a water (A) and acetonitrile $(\mathrm{ACN})$ gradient system. The gradient elution program was $7.5-55 \% \mathrm{~B}$ (0-40 $\mathrm{min}), 55-100 \% \mathrm{~B}$ (40-50 min), and $100-100 \% \mathrm{~B}(50-60 \mathrm{~min})$. The UV detector was set at $280 \mathrm{~nm}$ with full spectral scanning from 200 to $600 \mathrm{~nm}$. Chromatography was performed at room temperature with a flow rate of $0.7 \mathrm{~mL} / \mathrm{min}$, and the injection volume was $10 \mu \mathrm{L}$. Identification of the EtOAc extract was carried out by UVDAD and ESI-MS. LC-ESI-MS analysis was performed using an ion trap mass spectrometer (Finnigan LCQ Advantage Max, Thermo) equipped with an electrospray ionization source as interface, coupled to a Finnigan Surveyor HPLC system (Thermo Electron Corporation). Ultrapure helium (He) was used as the collision gas, and pure nitrogen $\left(\mathrm{N}_{2}\right)$ was used as the nebulizing gas. The mass spectrometer conditions were optimized using flow injection analysis of crude 
extract without HPLC column and were as follows: source voltage $4.8 \mathrm{kV}$, capillary voltage $3.0 \mathrm{~V}$, sheath gas flow rate $8.0 \mathrm{~mL} / \mathrm{min}$; and capillary temperature $275.0^{\circ} \mathrm{C}$; the first event was a full (200 to 700) MS scan $\left(\mathrm{MS}^{1}\right)$; during the second event, the main ion recorded was isolated and selectively fragmented in the ion trap $\left(\mathrm{MS}^{2}\right)$; collision energy for fragmentation $40 \mathrm{eV} .{ }^{1} \mathrm{H}$ and ${ }^{13} \mathrm{C} \mathrm{NMR}$ spectra of the isolated pure compounds were recorded with a Bruker AV 600 instrument, using MeOH-d4 or DMSO-d6 as a solvent.

2.7. Measurement of Partition Coefficient and Settling Time for HSCCC. Two-phase solvent systems were tested by changing the volume of the solvent to obtain the optimum composition to yield suitable partition coefficient ( $K$ values). The $K$ values were determined as described [19]. Briefly, the composition of a two-phase solvent system was selected according to the $K$ of the target compounds of crude extract. Approximately $25 \mathrm{mg}$ of the crude extract was weighed in a $20 \mathrm{~mL}$ test tube to which $5 \mathrm{~mL}$ of each phase of the preequilibrated two-phase solvent system was added. After the tube was shaken vigorously, the solution was quickly separated for a moment. Then, the upper and lower phases were analyzed by HPLC to obtain the $K$ value of the target compound. The $K$ value was expressed as the peak area of the target compound in the upper phase divided by that of the lower phase. Settling time, which is closely correlated to retention of the stationary phase, was expressed as the time needed to form a clear layer between phases when each phase $(1: 1, \mathrm{v} / \mathrm{v})$ was mixed.

\subsection{Preparation of Two-Phase Solvent System and Sample} Solution for HSCCC. The two-phase solvent composed of $\mathrm{n}-$ hexane-ethyl acetate-methanol-water HEMWat, $1.5: 5: 1: 5$, $\mathrm{v} / \mathrm{v}$, and $3: 7: 5: 5, \mathrm{v} / \mathrm{v}$, was used for HSCCC separations. Each component of the solvent system was added to a separate funnel and thoroughly equilibrated at room temperature. Two phases were separated and degassed by sonication for $30 \mathrm{~min}$ before use. The sample solutions were prepared by dissolving $4.0 \mathrm{~g}$ of the crude extract in the mixture of upper and lower phases $(1: 1, \mathrm{v} / \mathrm{v})$ of the solvent system used for HSCCC separation.

2.9. HSCCC Separation. The multilayer coil column was entirely filled with the upper organic phase (stationary phase) at a flow rate of $10.0 \mathrm{~mL} / \mathrm{min}$. The lower phase was then pumped into the head of the inlet column at a flow rate of $5.0 \mathrm{~mL} / \mathrm{min}$, while the apparatus was run at a revolution speed of $400 \mathrm{rpm}$. After hydrodynamic equilibrium was established, as indicated by a clear mobile phase eluting at the tail outlet, the sample solution ( $4.0 \mathrm{~g}$ in $50 \mathrm{~mL}$ of each phase) was injected into the separation column through the injection valve. The effluent from the tail end of the column was continuously monitored by a connection to a coiled column with a UV detector at $280 \mathrm{~nm}$. Each peak fraction was collected in $25 \mathrm{~mL}$ tubes according to the elution profile. After the separation was complete, stationary phase retention was measured by collecting the column contents; this was done by forcing them out of the column with pressurized nitrogen gas.
TABLE 1: Inhibitory effects of the crude extracts and fractions of $P$. frutescens on rAR.

\begin{tabular}{lc}
\hline Sample & $\mathrm{IC}_{50}(\mu \mathrm{g} / \mathrm{mL})^{\mathrm{a}}$ \\
\hline MeOH extract & 9.34 \\
$n$-Hexane fr. & - \\
$\mathrm{CH}_{2} \mathrm{Cl}_{2}$ fr. & 9.06 \\
EtOAc fr. & 1.92 \\
$n$-Butanol fr. & 2.89 \\
Water fr. & - \\
Quercetin &
\end{tabular}

${ }^{\mathrm{a}} \mathrm{The}_{\mathrm{IC}} \mathrm{C}_{50}$ value was defined as the concentration at $50 \%$ inhibition.

${ }^{\mathrm{b}}$ Quercetin, positive control.

2.10. Assay for rAR Inhibitory Activity. Crude rAR was prepared as follows. Rat lenses were removed from closed male Sprague-Dawley rats weighing 250-280 g and frozen until required. The rat lens homogenate was prepared according to Hayman and Kinoshita with some modifications [20, 21]. A partially purified enzyme with a specific activity of $6.5 \mathrm{U} / \mathrm{mg}$ was routinely used to test enzyme inhibition. The partially purified material was separated into $1.0 \mathrm{~mL}$ aliquots and stored at $40^{\circ} \mathrm{C}$. rAR activity was assayed spectrophotometrically by measuring the decrease in NADPH absorption at $340 \mathrm{~nm}$ over a $4 \mathrm{~min}$ period with dl-glyceraldehyde substrate. Each $1.0 \mathrm{~mL}$ cuvette contained equal units of the enzyme, $0.10 \mathrm{M}$ sodium phosphate buffer ( $\mathrm{pH} 6.2$ ), and $0.3 \mathrm{mM}$ NADPH, with or without $10 \mathrm{mM}$ substrate and an inhibitor $[22,23]$. The concentration of inhibitors yielding $50 \%$ inhibition $\left(\mathrm{IC}_{50}\right)$ was calculated from the least-squares regression line of the logarithmic concentrations plotted against the residual activity.

\section{Results}

3.1. rAR Inhibitory Effects of the Crude Extracts. The purpose of this study was to identify a natural AR inhibitor from $P$. frutescens to be used in the treatment of diabetic complications. To identify the active compounds from $P$. frutescens, plant extracts were systematically divided into 6 fractions, which were then tested for AR inhibitory activity. The EtOAc fraction exhibited the strongest rAR inhibitory activity, with $\mathrm{IC}_{50} 1.92 \mu \mathrm{g} / \mathrm{mL}$ (Table 1). The $\mathrm{IC}_{50}$ for quercetin, a wellknown AR inhibitor used as the reference control in this study, was $2.29 \mu \mathrm{g} / \mathrm{mL}$. These results suggest that the EtOAc soluble fraction of $P$. frutescens contains abundant AR inhibitory compounds.

3.2. rAR Inhibitory Activities after HPLC Microfractionation. The EtOAc soluble fraction of $P$. frutescens inhibited rAR. Therefore, we sought to identify the rAR inhibitory compounds by combining HPLC microfractionation with a 96well enzyme assay. This enabled the biological activities to be efficiently matched with specific HPLC peaks (Figure 1). Inhibition was linked to a substance that eluted at peaks 2 and 4. The rAR inhibitory activity in the corresponding wells was 34.50 and $53.31 \%$, respectively. Similar inhibition values at peaks 1 (20.46\%), 3 (21.31\%), 5 (29.46\%), and $\mathbf{6}$ (22.94\%) were 
TABLE 2: Partition coefficient $K$-value of target compounds 1-6 in different two-phase solvent systems used in HSCCC.

\begin{tabular}{lccccccccccc}
\hline$n$-Hexane & EtOAc & MeOH & ACN & Water & $\mathbf{1}$ & $\mathbf{2}$ & $\mathbf{3}$ & $\mathbf{4}$ & $\mathbf{5}$ & $\mathbf{6}$ & Settling time $(\mathrm{s})$ \\
\hline 1.5 & 5 & 1.5 & 4.5 & & 0.93 & 0.95 & 0.79 & 1.41 & & & \\
1.5 & 5 & 1.5 & & 4 & 1.01 & 1.24 & 0.12 & 1.49 & & $>2.5$ & \\
1.5 & 5 & 1 & & 5 & 1.26 & 1.86 & 1.17 & 2.43 & & 12 \\
2 & 8 & 4 & & 6 & & & & & 4.22 & 2.6 & \\
3 & 7 & 3.5 & & 6.5 & & & & & 4.51 & 2.31 & 27 \\
3 & 7 & 5 & & 5 & & & & & 2.46 & 1.24 & 18 \\
\hline
\end{tabular}

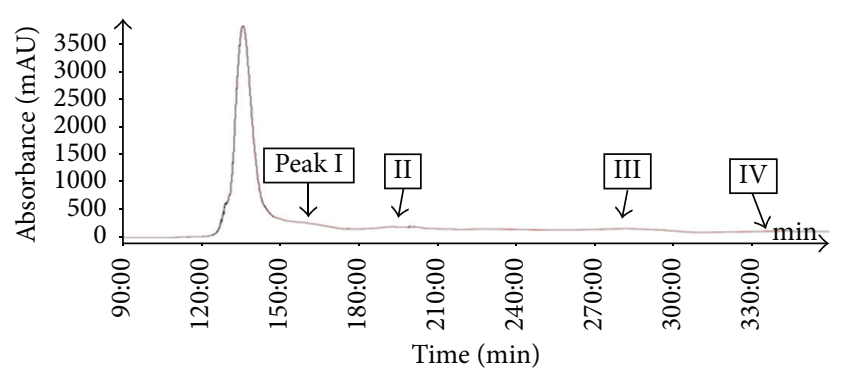

FIGURE 2: HSCCC separation of the EtOAc soluble fraction from the leaves of $P$. frutescens. Solvent system: n-hexane-ethyl acetatemethanol-water $(1.5: 5: 1: 5, \mathrm{v} / \mathrm{v})$; flow-rate, $5.0 \mathrm{~mL} / \mathrm{min}$; revolution speed, $400 \mathrm{rpm}$; sample size, $4.0 \mathrm{~g}$; injection volume, $50 \mathrm{~mL}$; detection wavelength, $280 \mathrm{~nm}$; stationary phase retention, 56\%. Peaks I, II, III, and IV in the HSCCC chromatogram correspond to compounds $3,1,2$, and 4 , respectively.

close to the hit limit. Further efforts to identify and characterize this substance are ongoing. Dereplication assays using HPLC play an important role in the search for active compounds from plants, providing rapid access to information concerning both the activity and localization of the activity in complex plant matrices. The active compounds at peaks 2 and $\mathbf{4}$ were tentatively identified as chlorogenic acid and rosmarinic acid by LC-ESI/MS ${ }^{\mathrm{n}}$. The negative ion mass spectra of peak 2 show an ion at $m / z 353(\mathrm{M}-\mathrm{H})^{-}$and fragment ions at $m / z 191$ [quinic acid-H] ${ }^{-}$and 179 [caffeic acid-H] [ $^{-}$these were compared to the elution order of caffeoylquinic acids reported in the literature [24]. Peak 2 was identified as chlorogenic acid. The positive ion mass spectra of peak 4 show an ion at $m / z 360.85[\mathrm{M}]^{+}$and fragment ions at $m / z 342.93$ [M$\left.\mathrm{H}_{2} \mathrm{O}\right]^{+}, 180.94$ [caffeic acid] $^{+}$, and 163.1 [caffeic acid esters] $^{+}$, which is consistent with the observation of $m / z 163$ in the positive ion mode, typical of caffeic acid esters [25, 26]. Peak 4 was identified as rosmarinic acid.

The quality of the assay was assessed using statistical parameters to ensure sufficient dynamic range and acceptable signal variability. The results were considered valid when $Z=$ $0.5, S / N=10$, and $S / B=4$. In general, the limiting value of 0.5 for the $Z^{\prime}$-factor indicates an excellent assay [17]. The standard deviation in the blank wells $(n=12)$ was $7.39 \%$, and thus the hit limit was set at $18.49 \%$. Calculated statistical parameters for the assay were excellent $\left(Z^{\prime}=0.96, S / N=12.12\right.$, and $S / B=13.46)$.

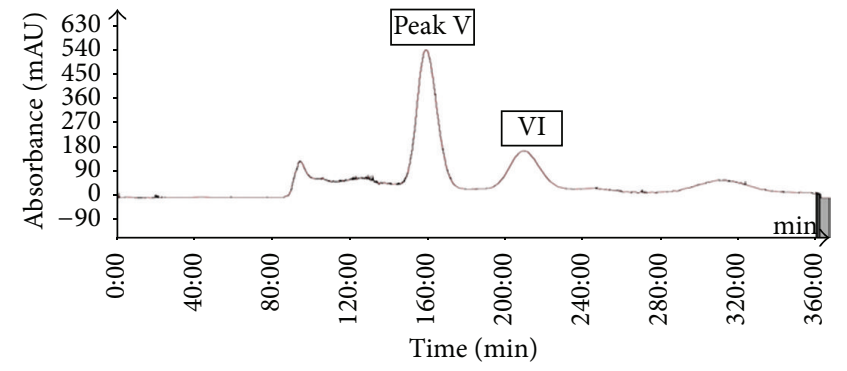

FIgURE 3: HSCCC chromatogram of $P$ frutescens after HSCCC separation. Solvent system: n-hexane-ethyl acetate-methanol-water $(3: 7: 5: 5, \mathrm{v} / \mathrm{v})$; flow rate, $5.0 \mathrm{~mL} / \mathrm{min}$; revolution speed, $400 \mathrm{rpm}$; sample size, $1.2 \mathrm{~g}$; injection volume, $50 \mathrm{~mL}$; detection wavelength, $280 \mathrm{~nm}$; stationary phase retention, 53\%. Peaks V and VI in the HSCCC chromatogram correspond to compounds $\mathbf{6}$ and $\mathbf{5}$, respectively.

3.3. HSCCC Separation. The most important step in the design of an HSCCC separation protocol is selection of the solvent system. Generally, the two-phase solvent system must satisfy the following requirements: (i) the settling time of the solvent system should ideally be shorter than $30 \mathrm{~s}$ to ensure satisfactory retention of the stationary phase, (ii) the partition coefficient $(K)$ of the target compounds should lie within the range $0.5 \leq K \leq 2.5$ for efficient separation, and (iii) the separation factor between the components $(\alpha=K 2 / K 1, K 2>$ $K 1)$ should be greater than $1.5[27,28]$. In this study, the $K$ values of 6 compounds were determined by HPLC, as described in the Materials and Methods. The measured $K$ values of each compound are summarized in Table 2. Based on the criteria for $K$ values in the range of $0.5-2.5$, one system was selected for further evaluation which was HEMWat $(1.5: 5: 1: 5, \mathrm{v} / \mathrm{v})$. As presented in Table 2, using HEMWat solvent systems, the $K$ values of compounds $\mathbf{1 - 4}$ were suitable, whereas those of compounds $\mathbf{5}$ and $\mathbf{6}$ were too great. Thus, HSCCC separation could not be performed using the single two-phase solvent. First, the $4.0 \mathrm{~g}$ quantity of EtOAc soluble fraction of $P$. frutescens was subjected to HSCCC using HEMWat solvent $(1.5: 5: 1: 5, \mathrm{v} / \mathrm{v})$. The separation time was $360 \mathrm{~min}$, and stationary phase retention was $56 \%$. As shown in Figure 2, there are 4 isolated peaks I-IV (corresponding to compounds $\mathbf{3}, \mathbf{1}$, 2, and 4, resp.). Peak I was collected from 150 to $174 \mathrm{~min}$, peak II from 186 to $200 \mathrm{~min}$, peak III from 258 to $300 \mathrm{~min}$, and peak IV from 330 to $345 \mathrm{~min}$ and were evaporated to yield $24.9,50.1,9.1$, and $549.1 \mathrm{mg}$ at $91.4,94.5,92.1$, and $97.4 \%$ purity 


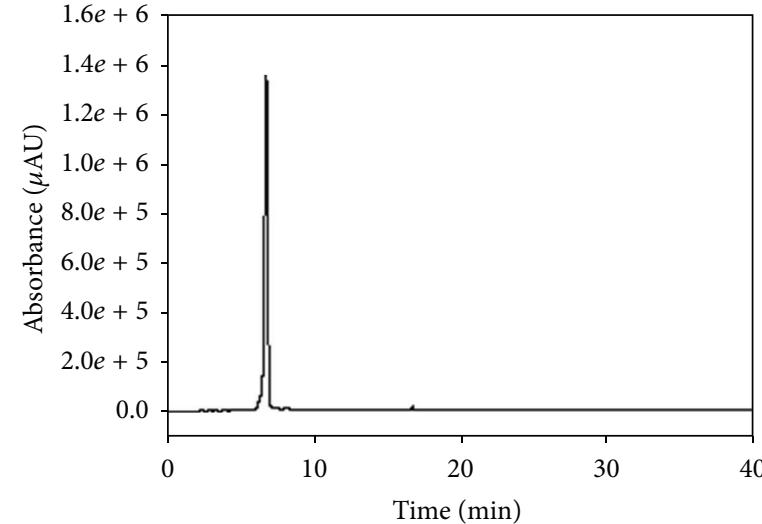

(1)

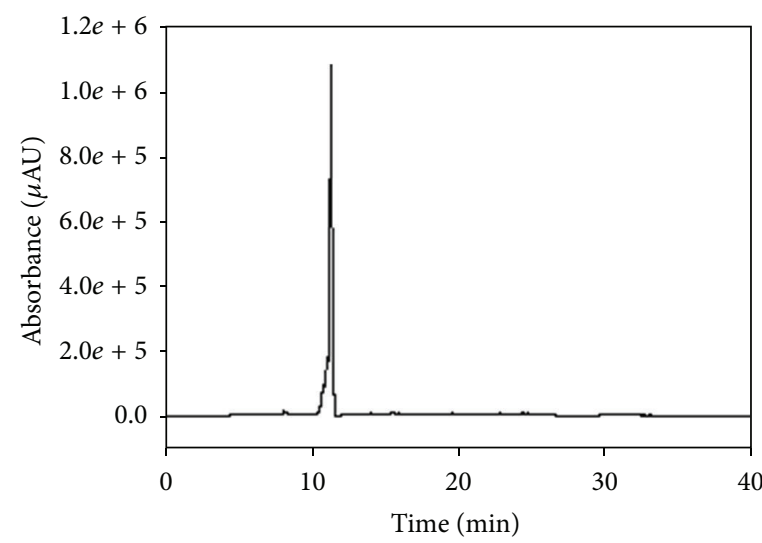

(3)

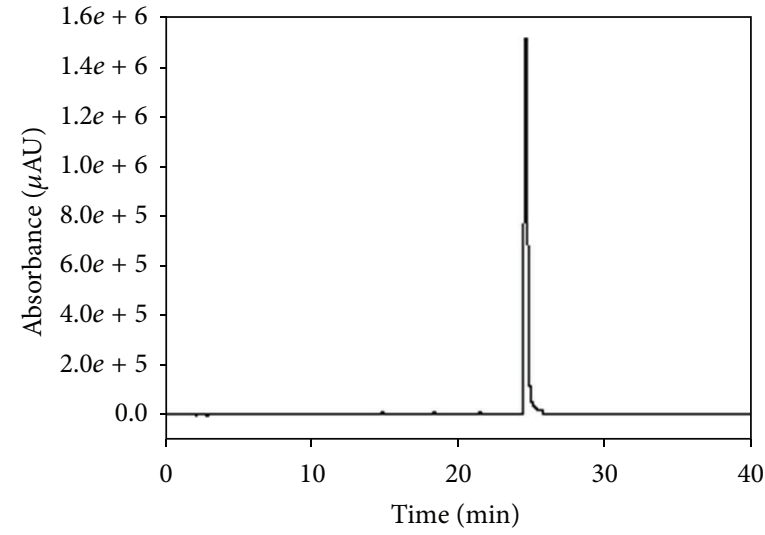

(5)

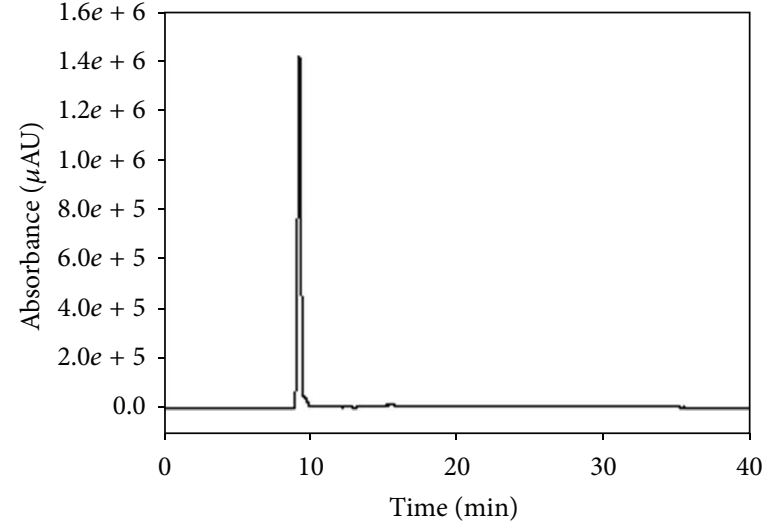

(2)

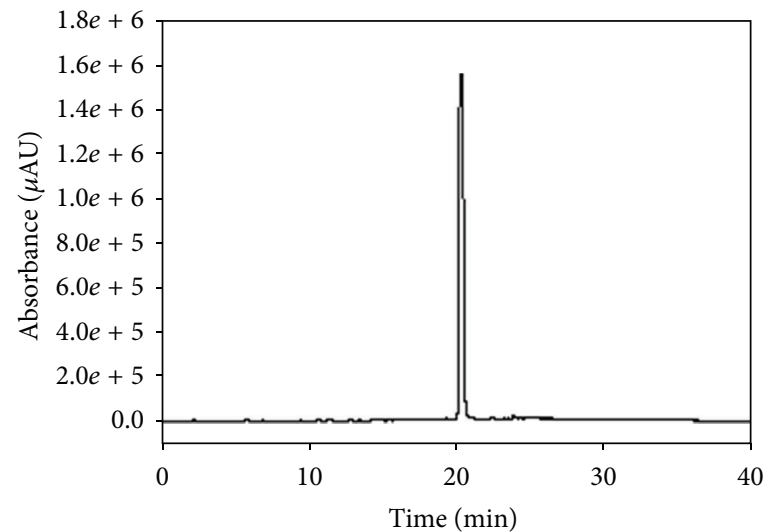

(4)

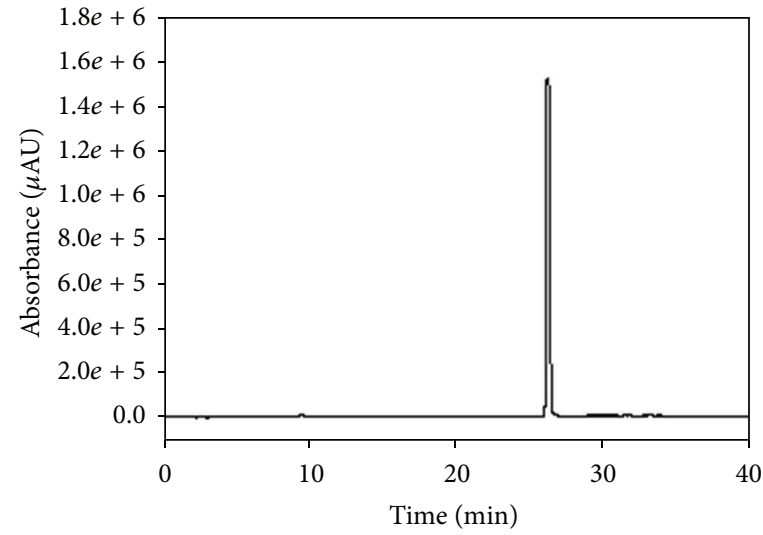

(6)

Figure 4: HPLC analysis of compounds 1-6 separated by HSCCC. Conditions: column, Eclipse SB-C18 Rapid Resolution column (150 $\times$ $4.6 \mathrm{~mm}, 5 \mu \mathrm{m}$, Agilent); column temperature, $30^{\circ} \mathrm{C}$; mobile phase, $0.1 \%$ TFA (solvent A) and acetonitrile (solvent B); HPLC analysis, linear gradient from 7.5 to $55 \% \mathrm{~B}(0-40 \mathrm{~min})$. Flow rate, $0.7 \mathrm{~mL} / \mathrm{min}$; detection, photodiode array detector; injection volume, $10 \mu \mathrm{L}$.

with recovery of $90,94,90$, and $98 \%$, respectively, as determined by HPLC. For collection of noneluted peak, V and VI in the first HSCCC, all fractions eluted after $350 \mathrm{~min}$ were combined and evaporated. The two-phase solvent system of HEMWat at ratio of $3: 7: 5: 5$ was suitable for the separation of compounds 5 and $\mathbf{6}$. Figure 3 shows HSCCC separation of the EtOAc soluble fraction after HSCCC separation with the HEMWat $(3: 7: 5: 5, \mathrm{v} / \mathrm{v})$ solvent system with $K$ values of 2.46 and 1.24 for compounds 5 and $\mathbf{6}$, respectively, and separated with good resolution. Peak V from 147 to $172 \mathrm{~min}$ and VI from 195 to $227 \mathrm{~min}$ were collected and concentrated. A total of 81.4 and $56.9 \mathrm{mg}$ of compounds 5 and $\mathbf{6}$ were obtained at 96.4 and 98.2\% purity with recovery of 94 and $95 \%$. HPLC analysis of compounds $\mathbf{1 - 6}$ is shown in Figure 4.

3.4. Structural Determination and $r A R$ Inhibitory Activity. The compounds were identified by comparing the LC-MS, 
$\mathrm{UV},{ }^{1} \mathrm{H}$-, and ${ }^{13} \mathrm{C}-\mathrm{NMR}$ to previously reported data. The compounds are protocatechuic acid (1), chlorogenic acid (2), caffeic acid (3), rosmarinic acid (4), luteolin (5), and methyl rosmarinic acid (6).

Compound 1. ${ }^{1} \mathrm{H}-\mathrm{NMR}\left(\mathrm{CD}_{3} \mathrm{OD}, 400 \mathrm{MHz}\right) \delta 6.79(1 \mathrm{H}, \mathrm{d}, J=$ $8.0 \mathrm{~Hz}), \delta 7.42(1 \mathrm{H}, \mathrm{dd}, J=8.0 \mathrm{~Hz}$ and $J=2.0 \mathrm{~Hz}), \delta 7.43(1 \mathrm{H}$, $\mathrm{d}, J=2.0 \mathrm{~Hz}) ;{ }^{13} \mathrm{C}-\mathrm{NMR}\left(\mathrm{CD}_{3} \mathrm{OD}, 100 \mathrm{MHz}\right) \delta 168.15(\mathrm{C}-7)$, 115.99 (C-2), 117.38 (C-5), 122.47 (C-6), 122.47 (C-1), 145.73 (C3), 150.85 (C-4); RT (retention time) $5.66 \mathrm{~min}$, ESI-MS $(\mathrm{m} / z)$ $155[\mathrm{M}+\mathrm{H}]^{+}$, MS-MS $(m / z) 109[\mathrm{M}-\mathrm{COOH}]^{+}$; UV $(\mathrm{MeCN}$, $\left.\lambda_{\max } \mathrm{nm}\right) 259 \mathrm{sh}, 294$. The ${ }^{1} \mathrm{H}-\mathrm{NMR},{ }^{13} \mathrm{C}-\mathrm{NMR}$, MS, and UV data for compound $\mathbf{1}$ are identical to those reported previously $[29,30]$. Compound 1 was identified as protocatechuic acid and did not exhibit inhibitory activity.

Compound 2. RT (retention time) $8.6 \mathrm{~min}$, ESI-MS $(\mathrm{m} / z)$ $353(\mathrm{M}-\mathrm{H})^{-}, 191$ [quinic acid-H] $]^{-}, 179$ [caffeic acid-H] ${ }^{-}$; UV $\left(\mathrm{MeCN}, \lambda_{\max } \mathrm{nm}\right) 298 \mathrm{sh}, 346(\max )$. The MS and UV data for compound 2 are identical to those reported previously in the literature [24]. Compound 2 was identified as chlorogenic acid and inhibited rAR in a concentration-dependent manner; its $\mathrm{IC}_{50}$ value was $3.16 \mu \mathrm{M}$, which is similar to that of quercetin $(5.07 \mu \mathrm{M})$.

Compound 3. ${ }^{1} \mathrm{H}-\mathrm{NMR}\left(\mathrm{CD}_{3} \mathrm{OD}, 400 \mathrm{MHz}\right) \delta 6.77(1 \mathrm{H}, \mathrm{d}$, $J=8.1 \mathrm{~Hz}, \mathrm{H}-5), \delta 7.03(1 \mathrm{H}, \mathrm{d}, J=2.0 \mathrm{~Hz}, \mathrm{H}-2), \delta 6.93(1 \mathrm{H}$, dd, $J=8.1 \mathrm{~Hz}$ and $J=2.0 \mathrm{~Hz}, \mathrm{H}-6) ;{ }^{13} \mathrm{C}-\mathrm{NMR}\left(\mathrm{CD}_{3} \mathrm{OD}\right.$, $100 \mathrm{MHz}) \delta 171.46$ (C-9), 115.96 (C-8), 147.22 (C-7), 116.91 (C-5), 115.51 (C-2), 123.27 (C-6), 128.23 (C-1), 147.45 (C-3), 149.87 (C-4); RT (retention time) $9.54 \mathrm{~min}$, ESI-MS $(\mathrm{m} / z)$ $181[\mathrm{M}+\mathrm{H}]^{+}$, MS-MS $(m / z) 135[\mathrm{M}-\mathrm{COOH}]^{+}$; UV $(\mathrm{MeCN}$, $\left.\lambda_{\max } \mathrm{nm}\right) 235 \mathrm{sh}, 323$. The ${ }^{1} \mathrm{H}-\mathrm{NMR},{ }^{13} \mathrm{C}-\mathrm{NMR}, \mathrm{MS}$, and UV data for compound 3 are identical to those reported in the literature [31,32]. Compound $\mathbf{3}$ was identified as caffeic acid, which showed weak inhibitory activity against rAR.

Compound 4. ${ }^{1} \mathrm{H}-\mathrm{NMR}\left(\mathrm{CD}_{3} \mathrm{OD}, 400 \mathrm{MHz}\right) \delta 6.61(\mathrm{dd}, J=$ $1.9 \mathrm{~Hz}$ and $J=8.0 \mathrm{~Hz}), \delta 6.69(\mathrm{~d}, J=8.0 \mathrm{~Hz}), \delta 6.75(\mathrm{~d}, J=$ $1.9 \mathrm{~Hz}), \delta 6.77(\mathrm{~d}, J=8.1 \mathrm{~Hz}), \delta 6.94(\mathrm{dd}, J=8.1 \mathrm{~Hz}$ and $J=$ $1.9 \mathrm{~Hz}), \delta 7.04(\mathrm{~d}, J=1.9 \mathrm{~Hz}), \delta 7.54(\mathrm{~d}, J=15.9 \mathrm{~Hz}), \delta 6.26$ $(\mathrm{d}, J=15.9 \mathrm{~Hz}), \delta 5.19(\mathrm{dd}, J=4.3 \mathrm{~Hz}$ and $J=8.2 \mathrm{~Hz}), \delta 3.00$ (dd, $J=8.2 \mathrm{~Hz}$ and $J=14.2 \mathrm{~Hz}), \delta 3.09(\mathrm{dd}, J=4.3 \mathrm{~Hz}$ and $J=14.2 \mathrm{~Hz}) ;{ }^{13} \mathrm{C}-\mathrm{NMR}\left(\mathrm{CD}_{3} \mathrm{OD}, 100 \mathrm{MHz}\right) \delta 147.22\left(\mathrm{C}-4^{\prime}\right)$, 150.15 (C-3'), 146.57 (C-3), 145.69 (C-4), 173.97 (C-9), 168.90 (C-9'), $148.16\left({\mathrm{C}-7^{\prime}}^{\prime}\right), 116.73\left(\mathrm{C}-8^{\prime}\right), 75.06$ (C-8); RT (retention time) $17.95 \mathrm{~min}$, ESI-MS $(\mathrm{m} / z) 361[\mathrm{M}+\mathrm{H}]^{+}$, MS-MS $(\mathrm{m} / z)$ $163[\mathrm{M}-\mathrm{COOH}]^{+}$; UV (MeCN, $\left.\lambda_{\max } \mathrm{nm}\right) 244,335$ (max). The ${ }^{1} \mathrm{H}-\mathrm{NMR},{ }^{13} \mathrm{C}-\mathrm{NMR}, \mathrm{MS}$, and UV data for compound $\mathbf{4}$ are identical to those reported previously $[25,26,33,34]$. Compound 4 was identified as rosmarinic acid. Compound 4 had the most potent rAR inhibitory activity $(2.77 \mu \mathrm{M})$.

Compound 5. RT (retention time) $22.27 \mathrm{~min}$, ESI-MS $(\mathrm{m} / z)$

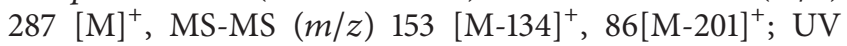
$\left(\mathrm{MeCN}, \lambda_{\max } \mathrm{nm}\right) 253,346$ (max). The MS and UV data for compound $\mathbf{5}$ are identical to those reported previously [35]. Compound 5 inhibited rAR in a concentration-dependent manner; its $\mathrm{IC}_{50}$ value was $6.34 \mu \mathrm{M}$, similar to that of quercetin $(5.07 \mu \mathrm{M})$.

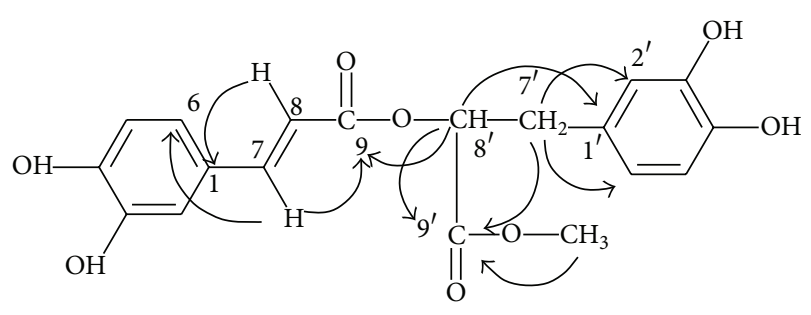

FIGURE 5: Main correlation HMBC for 6.

Compound 6. ${ }^{1} \mathrm{H}-\mathrm{NMR}\left(\mathrm{CD}_{3} \mathrm{OD}, 600 \mathrm{MHz}\right) \delta 6.57(\mathrm{dd}, J=$ $1.9 \mathrm{~Hz}$ and $J=8.0 \mathrm{~Hz}), \delta 6.7(\mathrm{~d}, J=8.1 \mathrm{~Hz}), \delta 6.71(\mathrm{~d}, J=$ $1.7 \mathrm{~Hz}), \delta 6.78(\mathrm{~d}, J=8.1 \mathrm{~Hz}), \delta 6.96(\mathrm{dd}, J=8.2 \mathrm{~Hz}$ and $J=$ $1.5 \mathrm{~Hz}), \delta 7.05(\mathrm{~d}, J=1.7 \mathrm{~Hz}), \delta 7.55(\mathrm{~d}, J=15.8 \mathrm{~Hz}), \delta 6.26$ $(\mathrm{d}, J=15.9 \mathrm{~Hz}), \delta 5.19(\mathrm{dd}, J=5.1 \mathrm{~Hz}$ and $J=7.6 \mathrm{~Hz}), \delta 3.69$ $(\mathrm{s}), \delta 3.04(\mathrm{dd}, J=8 \mathrm{~Hz}$ and $J=14 \mathrm{~Hz}), \delta 3.09(\mathrm{dd}, J=4.2 \mathrm{~Hz}$ and $J=14.2 \mathrm{~Hz}) ;{ }^{13} \mathrm{C}-\mathrm{NMR}\left(\mathrm{CD}_{3} \mathrm{OD}, 150 \mathrm{MHz}\right) \delta 126.20$ (C1), 112.76 (C2), 145.43 (C3), 148.42 (C4), 114.92 (C5), 121.82 (C6), 146.56 (C7), 113.93 (C8), 166.93 (C9), $127.36\left(\mathrm{Cl}^{\prime}\right), 116.14$ $\left(\mathrm{C} 2^{\prime}\right), 144.82\left(\mathrm{C}^{\prime}\right), 143.99\left(\mathrm{C} 4^{\prime}\right), 115.12\left(\mathrm{C}^{\prime}\right), 120.40\left(\mathrm{C}^{\prime}\right)$, $36.50\left(\mathrm{C}^{\prime}\right), 73.28\left(\mathrm{C}^{\prime}\right), 170.78\left(\mathrm{C}^{\prime}\right), 51.27\left({\mathrm{C} 10^{\prime}}^{\prime}\right)$. RT (retention time) $23.82 \mathrm{~min}$, ESI-MS $(\mathrm{m} / z) 374[\mathrm{M}]^{+}$, MS-MS $(\mathrm{m} / z)$ (\% rel. int.) 163(100); UV (MeCN, $\left.\lambda_{\max } \mathrm{nm}\right) 223 \mathrm{sh}, 330$. A cross peak between C-9 and the methyl proton was observed by a heteronuclear multiple bond connectivity (HMBC) experiment (Figure 5). The ${ }^{1} \mathrm{H}-\mathrm{NMR},{ }^{13} \mathrm{C}-\mathrm{NMR}, \mathrm{HMBC}$, MS, and UV data for compound $\mathbf{6}$ are identical to those reported previously [36]. Compound $\mathbf{6}$ was identified as methyl rosmarinic acid. Compound 6 inhibited rAR in a concentration-dependent manner; its IC $_{50}$ was $4.03 \mu \mathrm{M}$, significantly lower than that of quercetin $(5.07 \mu \mathrm{M})$.

\section{Conclusions}

Crude extracts of the aerial portion of $P$. frutescens obtained by extraction with $99.5 \%$ methanol showed considerable rAR inhibitory activity. The EtOAc soluble fraction of the crude extract exhibited remarkable inhibitory activity against rAR $\left(\mathrm{IC}_{50}=1.92 \mu \mathrm{g} / \mathrm{mL}\right)$. Therefore, an investigation of inhibitory compounds from an EtOAc soluble fraction of the crude extract was followed by an effort to identify the inhibitory compounds by combining HPLC microfractionation with a 96-well enzyme assay. The rAR inhibitory activity profile showed that peaks $\mathbf{2}$ and $\mathbf{4}$ exhibit potent inhibitory activity. Structural analyses of these peaks were then carried out by LC-MS ${ }^{\mathrm{n}}$. The inhibitory compounds were tentatively identified as chlorogenic acid and rosmarinic acid. Furthermore, in a search for additional rAR inhibiting compounds, 6 pure compounds with different levels of rAR inhibitory activity were isolated from an EtOAc soluble fraction by HSCCC and identified as protocatechuic acid (1), chlorogenic acid (2), caffeic acid (3), rosmarinic acid (4), luteolin (5), and methyl rosmarinic acid (6). Specifically, rosmarinic acid exhibited the most potent AR inhibitory activity with an $\mathrm{IC}_{50}$ of $2.77 \mu \mathrm{M}$ (Table 3). The HPLC microfractionation plus enzyme assay system generated biological and chemical information and 
TABLE 3: Inhibitory effects of compounds 1-6 isolated from EtOAcsoluble fractions of $P$. frutescens extract on $\mathrm{rAR}$.

\begin{tabular}{lcc}
\hline Number & Compound & $\mathrm{IC}_{50}(\mu \mathrm{M})^{\mathrm{a}}$ \\
\hline $\mathbf{1}$ & Protocatechuic acid & - \\
$\mathbf{2}$ & Chlorogenic acid & 3.16 \\
$\mathbf{3}$ & Caffeic acid & - \\
$\mathbf{4}$ & Rosmarinic acid & 2.77 \\
$\mathbf{5}$ & Luteolin & 6.34 \\
$\mathbf{6}$ & Methyl rosmarinic acid $^{\mathrm{b}}$ & 4.03 \\
& Quercetin $^{\mathrm{b}}$ & 5.07 \\
\hline
\end{tabular}

${ }^{\mathrm{a}}$ The $\mathrm{IC}_{50}$ value was defined as the concentration at $50 \%$ inhibition.

${ }^{\mathrm{b}}$ Quercetin, positive control.

provided a valuable tool for screening and identification of rAR inhibitors in complex samples.

\section{Conflict of Interests}

The authors have declared that there is no conflict of interests.

\section{Acknowledgments}

This research was supported by the Ministry for Food, Agriculture, Forestry and Fisheries (112085-3), the ReSEAT Program of KISTI (Korea Institute of Science and Technology Information), and the Basic Science Research Program through the National Research Foundation of Korea (NRF) funded by the Ministry of Education (NRF2012R1A1A2008842).

\section{References}

[1] M. Brownlee, "Biochemistry and molecular cell biology of diabetic complications," Nature, vol. 414, no. 6865, pp. 813-820, 2001.

[2] P. J. Oates and B. L. Mylari, "Aldose reductase inhibitors: therapeutic implications for diabetic complications," Expert Opinion on Investigational Drugs, vol. 8, no. 12, pp. 2095-2119, 1999.

[3] D. R. Tomlinson, E. J. Stevens, and L. T. Diemel, "Aldose reductase inhibitors and their potential for the treatment of diabetic complications," Trends in Pharmacological Sciences, vol. 15, no. 8, pp. 293-297, 1994.

[4] R. L. Engerman and T. S. Kern, "Aldose reductase inhibition fails to prevent retinopathy in diabetic and galactosemic dogs," Diabetes, vol. 42, no. 6, pp. 820-825, 1993.

[5] A. Bhatnagar and S. K. Srivastava, "Aldose reductase: congenial and injurious profiles of an enigmatic enzyme," Biochemical Medicine and Metabolic Biology, vol. 48, no. 2, pp. 91-121, 1992.

[6] P. Raskin and J. Rosenstock, "Aldose reductase inhibitors and diabetic complications," American Journal of Medicine, vol. 83, no. 2, pp. 298-306, 1987.

[7] T. J. Ha, J. H. Lee, M. H. Lee et al., "Isolation and identification of phenolic compounds from the seeds of Perilla frutescens (L.) and their inhibitory activities against $\alpha$-glucosidase and aldose reductase," Food Chemistry, vol. 135, no. 3, pp. 1397-1403, 2012.
[8] J.-H. Liu, A. Steigel, E. Reininger, and R. Bauer, "Two new prenylated 3-benzoxepin derivatives as cyclooxygenase inhibitors from Perilla frutescens var. acuta," Journal of Natural Products, vol. 63, no. 3, pp. 403-405, 2000.

[9] H. Takeda, M. Tsuji, T. Matsumiya, and M. Kubo, "Identification of rosmarinic acid as a novel antidepressive substance in the leaves of Perilla frutescens Britton var. acuta Kudo (Perillae Herba)," Japanese Journal of Psychopharmacology, vol. 22, no. 1, pp. 15-22, 2002.

[10] K. N. Lee, H. H. Shin, D. S. Han et al., "Development of anticancer agents from Korean medicinal plants. Part 5. Cytotoxic activity of the butanol soluble fraction of Perilla frutescens against human skin melanoma cells," SaengyakHakhoechi, vol. 28, no. 4, pp. 264-270, 1997.

[11] Y. Nakamura, Y. Ohto, A. Murakami, and H. Ohigashi, "Superoxide scavenging activity of rosmarinic acid from Perilla frutescens britton var. acuta f. viridis," Journal of Agricultural and Food Chemistry, vol. 46, no. 11, pp. 4545-4550, 1998.

[12] H. Ueda, C. Yamazaki, and M. Yamazaki, "Luteolin as an antiinflammatory and anti-allergic constituent of Perilla frutescens," Biological and Pharmaceutical Bulletin, vol. 25, no. 9, pp. 11971202, 2002.

[13] J. H. Chen, Z. H. Xia, and R. X. Tan, "High-performance liquid chromatographic analysis of bioactive triterpenes in Perilla frutescens," Journal of Pharmaceutical and Biomedical Analysis, vol. 32, no. 6, pp. 1175-1179, 2003.

[14] N. S. Kang and J. H. Lee, "Characterisation of phenolic phytochemicals and quality changes related to the harvest times from the leaves of Korean purple perilla (Perilla frutescens)," Food Chemistry, vol. 124, no. 2, pp. 556-562, 2011.

[15] Y. Peng, J. Ye, and J. Kong, "Determination of phenolic compounds in Perilla frutescens L. by capillary electrophoresis with electrochemical detection," Journal of Agricultural and Food Chemistry, vol. 53, no. 21, pp. 8141-8147, 2005.

[16] M. Öztürk, M. E. Duru, B. Ince, M. Harmandar, and G. Topçu, "A new rapid spectrophotometric method to determine the rosmarinic acid level in plant extracts," Food Chemistry, vol. 123, no. 4, pp. 1352-1356, 2010.

[17] J. H. Zhang, T. D. Chung, and K. R. Oldenburg, "A simple statisticalprarameter for use in evaluation and validation of high troughputscreening assay," Journal of Biomolecular Screening, vol. 4, no. 2, pp. 67-73, 1999.

[18] S. Bollini, J. J. Herbst, G. T. Gaughan et al., "High-throughput fluorescence polarization method for identification of FKBP12 ligands," Journal of Biomolecular Screening, vol. 7, no. 6, pp. 526530, 2002.

[19] Y. S. Lee, S. H. Kim, J. K. Kim et al., "Rapid identification and preparative isolation of antioxidant components in licorice," Journal of Separation Science, vol. 33, no. 4-5, pp. 664-671, 2010.

[20] S. Hayman and J. H. Kinoshita, "Isolation and properties of lens aldose reductase," The Journal of Biological Chemistry, vol. 240, pp. 877-882, 1965.

[21] Y. S. Lee, Y.-H. Kang, J.-Y. Jung et al., "Inhibitory constituents of aldose reductase in the fruiting body of Phellinus linteus," Biological and Pharmaceutical Bulletin, vol. 31, no. 4, pp. 765-768, 2008.

[22] K. Kawanishi, H. Ueda, and M. Moriyasu, "Aldose reductase inhibitors from the nature," Current Medicinal Chemistry, vol. 10, no. 15, pp. 1353-1374, 2003.

[23] J. Á. de la Fuente and S. Manzanaro, "Aldose reductase inhibitors from natural sources," Natural Product Reports, vol. 20, no. 2, pp. 243-251, 2003. 
[24] M. N. Clifford, K. L. Johnston, S. Knight, and N. Kuhnert, "Hierarchical scheme for LC-MSn identification of chlorogenic acids," Journal of Agricultural and Food Chemistry, vol. 51, no. 10, pp. 2900-2911, 2003.

[25] R. J. Grayer, M. R. Eckert, N. C. Veitch et al., "The chemotaxonomic significance of two bioactive caffeic acid esters, nepetoidins A and B, in the Lamiaceae," Phytochemistry, vol. 64, no. 2, pp. 519-528, 2003.

[26] M. B. Hossain, D. K. Rai, N. P. Brunton, A. B. Martin-Diana, and A. C. Barry-Ryan, "Characterization of phenolic composition in lamiaceae spices by LC-ESI-MS/MS," Journal of Agricultural and Food Chemistry, vol. 58, no. 19, pp. 10576-10581, 2010.

[27] Y. Ito, "Golden rules and pitfalls in selecting optimum conditions for high-speed counter-current chromatography," Journal of Chromatography A, vol. 1065, no. 2, pp. 145-168, 2005.

[28] H. Guzlek, P. L. Wood, and L. Janaway, "Performance comparison using the GUESS mixture to evaluate counter-current chromatography instruments," Journal of Chromatography A, vol. 1216, no. 19, pp. 4181-4186, 2009.

[29] W. Peng, T. Han, Y. Wang, W.-B. Xin, C.-J. Zheng, and L.-P. Qin, "Chemical constituents of the aerial part of Atractylodes macrocephala," Chemistry of Natural Compounds, vol. 46, no. 6, pp. 959-960, 2011.

[30] C. Dai, P. Liu, C. Liu, B. Wang, and R.-Y. Chen, "Studies on chemical constituents from moss Rhodobryum roseum II," China Journal of Chinese Materia Medica, vol. 31, no. 13, pp. 1080-1082, 2006.

[31] H. Li, Y. Luo, Z. He, and G. Zhang, "Chemical constituents from Lonicera saccata," Chinese Journal of Applied and Environmental Biology, vol. 13, no. 2, pp. 188-191, 2007.

[32] M. Zhang, C. F. Zhang, and Z. T. Wang, "The chemical constituents of Ligularia pleurocaulis," Acta Pharmaceutica Sinica, vol. 40, no. 6, pp. 529-532, 2005.

[33] X.-M. Wei, J.-K. Cheng, D.-L. Cheng, and L.-M. Gao, "Chemical constituents from Clinopodium urticifolium," Journal of the Chinese Chemical Society, vol. 51, no. 5, pp. 1043-1049, 2004.

[34] T. Satake, K. Kamiya, Y. Saiki et al., "Studies on the constituents of fruits of Helicteres isora L.," Chemical and Pharmaceutical Bulletin, vol. 47, no. 10, pp. 1444-1447, 1999.

[35] M. Biesaga and K. Pyrzynska, "Liquid chromatography/tandem mass spectrometry studies of the phenolic compounds in honey," Journal of Chromatography A, vol. 1216, no. 38, pp. 66206626, 2009.

[36] Z. J. Wang, Y. Y. Zhao, B. Wang, T. M. Ai, and Y. Y. Chen, “Depsides from Prunella vulgaris," Chinese Chemical Letters, vol. 11, no. 11, pp. 997-1000, 2000. 

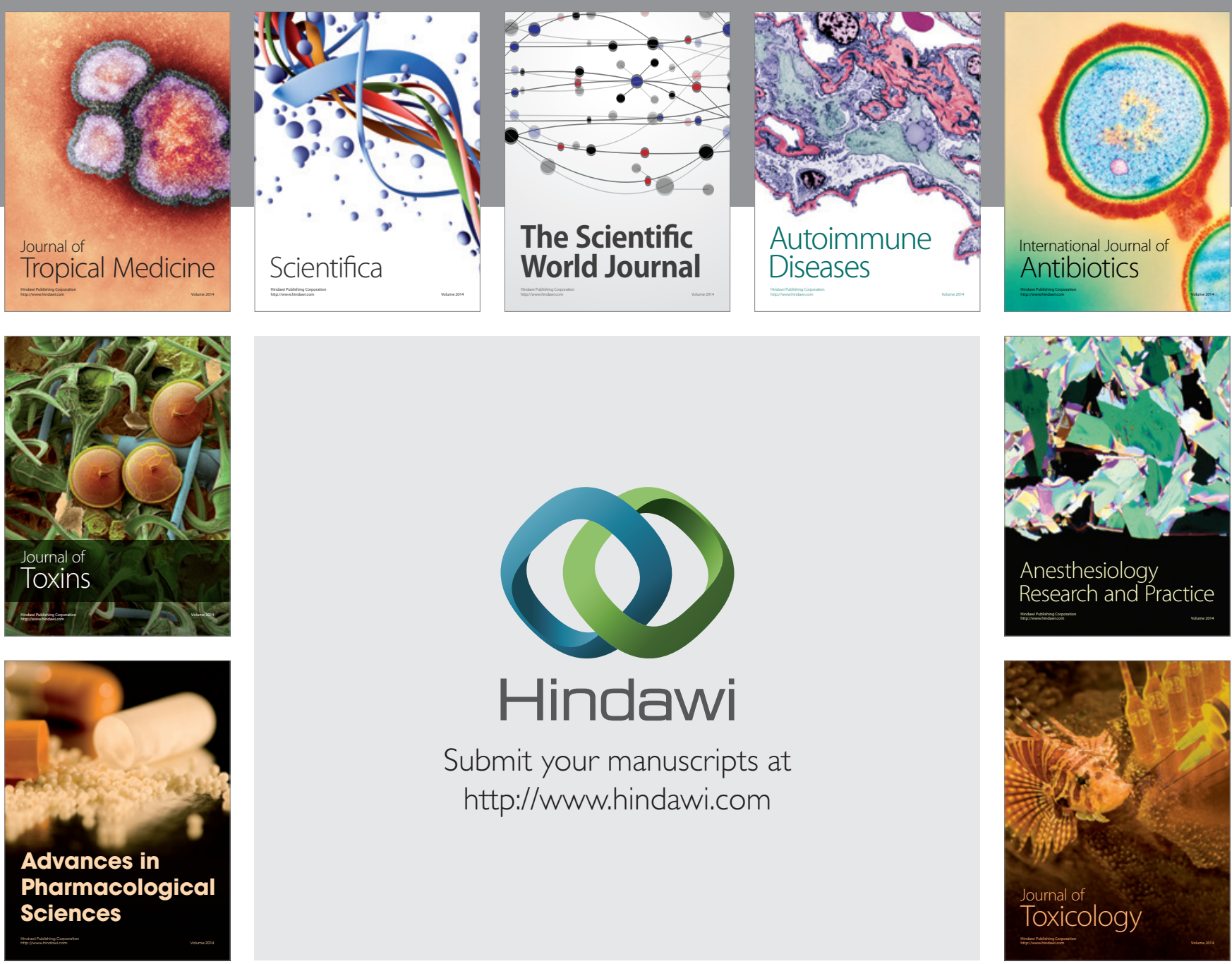

\section{Hindawi}

Submit your manuscripts at

http://www.hindawi.com
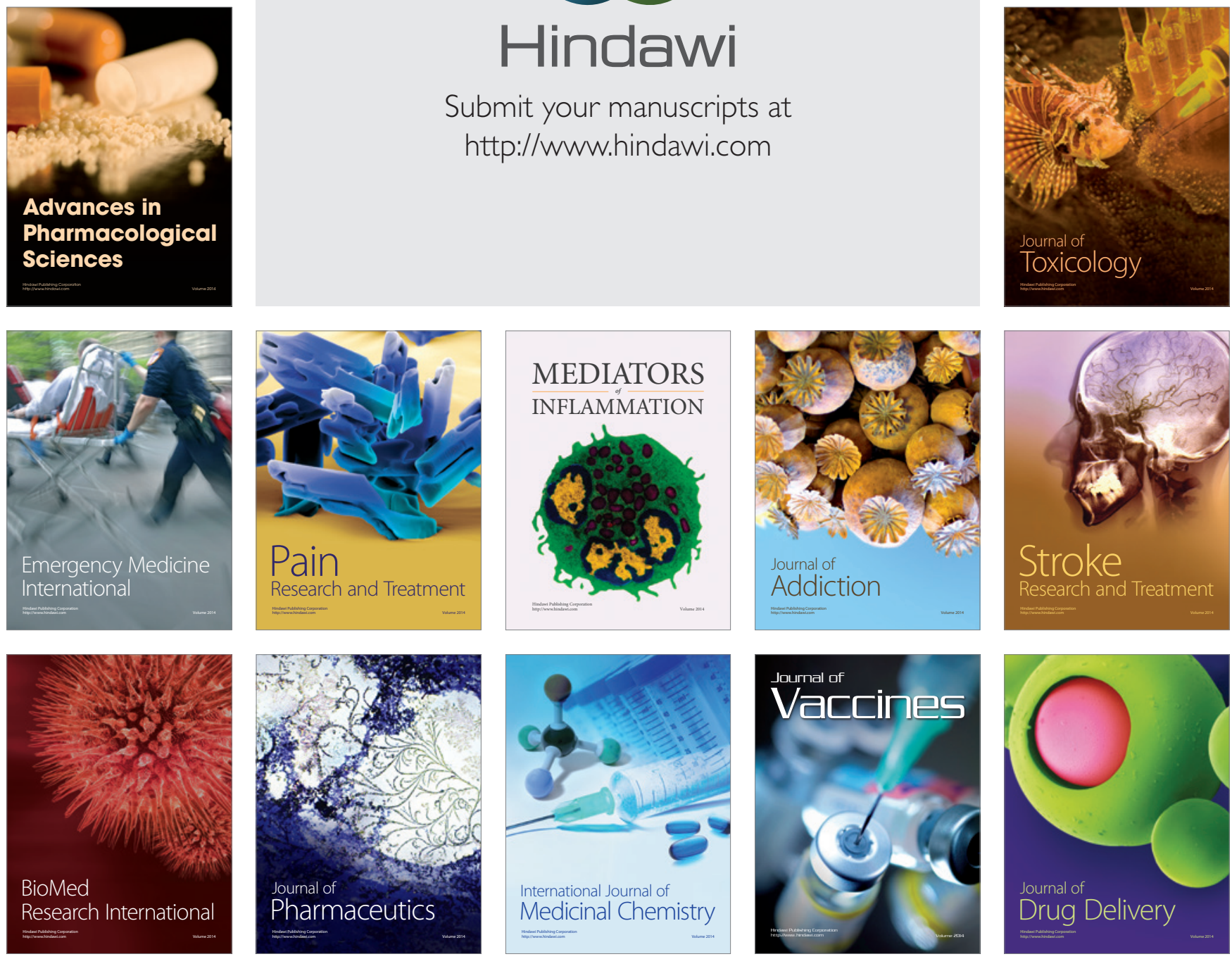